\section{Kinematic and Kinetic Analysis of Horticultural Activities for Postural Control and Balance Training}

\author{
A-Young Lee and Sin-Ae Park ${ }^{1}$ \\ Department of Environmental Health Science, Sanghuh College of Life \\ Science, Konkuk University, Seoul 05029, South Korea
}

\section{Young-Jin Moon}

Department of Sport Science, Chungnam National University, Daejeon 34134, South Korea

\section{Ki-Cheol Son \\ Department of Environmental Health Science, Sanghuh College of Life Science, Konkuk University, Seoul 05029, South Korea}

Additional index words. gardening, ground reaction force, electromyography, horticultural therapy, physical rehabilitation, 3D motion analysis

\begin{abstract}
The objective of this study was to analyze the kinematic and kinetic characteristics of eight horticultural activities (HAs): digging, raking, sowing seeds, transplanting plants, near-distance weeding, far-distance weeding, low-height harvesting, and high-height harvesting. Twenty-four male university students (average age, $\mathbf{2 3 . 4} \pm \mathbf{2 . 9}$ years) participated in this study. Balance and postural stability factors [e.g., center of mass (CoM), ground reaction force (GRF), and center of pressure (CoP)] and postural control strategy factors (e.g., joint angles, joint moment, and muscle activation of the trunk and lower limbs) were assessed using a three-dimensional (3D) motion analysis system, force platform, and surface electromyography. A total of eight HAs were distinguished in three motions: stepping, squatting, and stooping. In performing the eight HAs, CoM shifting occurred and balance of the subjects became unstable. These forced compensatory motor strategies to maintain balance by exertion of GRF from the two feet, movement of the $\mathrm{CoP}$, and a combination of musculoskeletal system exercises of the lower limbs and trunk occurred. The kinematic and kinetic characteristics of lower limb motions were significantly different across the HAs $(P=0.05)$. The kinematic and kinetic characteristics of HAs were similar to those of the functional tasks during balance improvement training motions and activities of daily living. The current study provides useful reference data for developing a horticultural therapy program for balance improvement in patients who need physical rehabilitation.
\end{abstract}

Falling leads to serious physical damage, such as hip and knee joint fractures. The main cause of falling is a loss of postural control ability resulting from a decrease in balance (Hatch et al., 2003). Balance is a fundamental factor in human movement and postural control, and is generally defined as the ability to maintain the CoM of the body within the base of support (BoS) (Hrysomallis, 2011). Specifically, dynamic balance is the ability to maintain postural stability against changes in $\mathrm{CoM}$ and BoS that occur during bodily movements (Shin and Demura, 2012). Recovery of body balance and postural stability is generated through postural control. Motor control in the central nervous system results in coordinated movements in the musculo-

Received for publication 5 July 2018. Accepted for publication 30 July 2018.

This study was supported by the KU Research Professor Program of Konkuk University. ${ }^{1}$ Corresponding author. E-mail: sapark42@konkuk. ac.kr. skeletal system as a strategy for postural control (Horak, 2006).

To investigate the characteristics of motor and postural control during human movement, the kinetics and kinematics of movement are described using various measurement instruments, such as a 3D motion analysis system, a GRF platform, and an electromyography (EMG) device. The gold standard for the analysis of human kinematics and kinetics is using a camera-based motion analysis system in combination with measurement devices such as GRF and EMG (Aurbach et al., 2017). On the basis of the characteristics of the movement and postural control identified through kinetic and kinematic analyses, rehabilitation experts (e.g., occupational therapists, clinical rehabilitation specialists, exercise prescribers) develop appropriate rehabilitation plans and methods (Murphy et al., 2006).

Meanwhile, HAs consist of growing activities such as digging, raking, sowing seeds, transplanting plants, and watering. The detailed activities within HAs include various motions such as sitting, walking, bending, stretching, and lifting (Park and Shoemaker,
2009; Verra et al., 2012). Park and Shoemaker (2009) reported that motions requiring waist and lower limb movements, such as bending $(82 \%)$, walking (59\%), and lifting (47\%), were performed mainly during HAs. In addition, researchers have expected that the various motions in HAs involve 1) combined exercises in which joints and muscles are used together, 2) weight-bearing exercises, and 3) movements during which the weight center of gravity changes (Chen and Janke, 2012; Park et al., 2013, 2014; Turner et al., 2002).

Therefore, the objective of the current study was to examine the kinetic and kinematic characteristics (e.g., CoM and $\mathrm{CoP}$ ) of the trunk and lower limbs during HAs to establish baseline data on postural control balance training using a very similar group. The kinematic and kinetic data of HA motions will be useful for the application of HAs as rehabilitation treatment.

\section{Materials and Methods}

Subjects

The research volunteer list at Konkuk University and Sahmyook University in Seoul, South Korea, was used to recruit a convenience sample of male subjects in their 20s. Subjects who volunteered to participate in this study were recruited through advertisements in the universities. Moreover, the researchers contacted the subjects via telephone or through face-to-face contact, providing explanations about the objective of the study, procedures, schedules, and requirements. All subjects completed the agreement form before participating in the experiment. The selection criteria for the subjects included no prior surgery in the lower limbs or spine within 5 years, and no musculoskeletal or neurologic problems (Kulas et al., 2012). The final sample consisted of 24 male university students age 23.4 \pm 2.9 years (Table 1 ). The sample size was based on the previous studies about assessment of control mechanisms during upright standing (Termoz et al., 2008) and investigation of the motion characteristics of lower limbs during daily living activities such as stooping, squatting, and standing (Hwang

Table 1. Descriptive characteristics of the subjects $(\mathrm{N}=24)$ participating in the study.

\begin{tabular}{lr}
\hline Variable & Mean $\pm \mathrm{SD}$ \\
\hline Age $(\mathrm{yr})$ & $23.4 \pm 2.9$ \\
Height $(\mathrm{cm})$ & $173.3 \pm 4.9$ \\
Body weight $(\mathrm{kg})$ & $68.8 \pm 8.7$ \\
Body composition & \\
$\quad$ Body mass index $\left(\mathrm{kg} \cdot \mathrm{m}^{-2}\right)$ & $22.8 \pm 2.4$ \\
$\quad$ Fat $(\mathrm{g})$ & $13.2 \pm 4.8$ \\
$\quad$ Lean $(\mathrm{g})$ & $51.9 \pm 4.8$ \\
$\quad$ Percent fat $(\%)$ & $18.3 \pm 4.7$ \\
Leg length $(\mathrm{cm})^{\mathrm{z}}$ & $99.5 \pm 4.6$ \\
\hline
\end{tabular}

${ }^{\mathrm{z}}$ Assessed as the distance from the right anterior superior iliac spine to the medial malleolus of the right leg by using tapeline (model Rollfix; Hoechstmass, Sulzbach, Germany) (Sabharwal and Kumar, 2008).

${ }^{\mathrm{y}}$ Measured using a body fat analyzer (ioi 353; Jawon Medical, Gyeongsan, South Korea) 
et al., 2009; Weaver et al., 2017). The mean body mass index was $22.8 \pm 2.4 \mathrm{~kg} \cdot \mathrm{m}^{-2}$, which is within the normal range (World Health Organization, 1995).

At the completion of the study, the subjects received $\$ 15$ as an incentive. This study was approved by the Institutional Review Board of Konkuk University (7001355201604-HR-115).

\section{Experimental conditions and HAs}

The study was performed in a motor mechanics laboratory at Korea Institute of Sport Science in Seoul, South Korea. A garden bed $(0.6 \mathrm{~m} \times 0.9 \mathrm{~m} \times 0.2 \mathrm{~m})$ was previously installed in the laboratory (Fig. 1). The initial positioning required subjects to stand with their feet at shoulder width in the middle of the garden bed with an anatomic posture at $0^{\circ}$ of the lower limb joint while holding the gardening tool for HAs with their right hand.
Six common HAs such as digging, raking, sowing seeds, transplanting plants, weeding, and harvesting were performed (Table 2). To ensure that all subjects performed the HAs in the same way, a standard operating procedure for the HAs was developed previously by six experts in the field of horticultural therapy, horticultural science, and motion dynamics (Park et al., 2014) (Table 2).

The researchers provided the subjects with a demonstration and oral explanation of the HAs before each activity was performed. The subjects performed each HA twice with a 30 -s resting period between each activity. The total experiment time for each subject was 60 min on average.

\section{Measurements}

Subject characteristics. Subject demographic information, including height, body composition, and leg length, was collected before starting the experiment. Height was
A
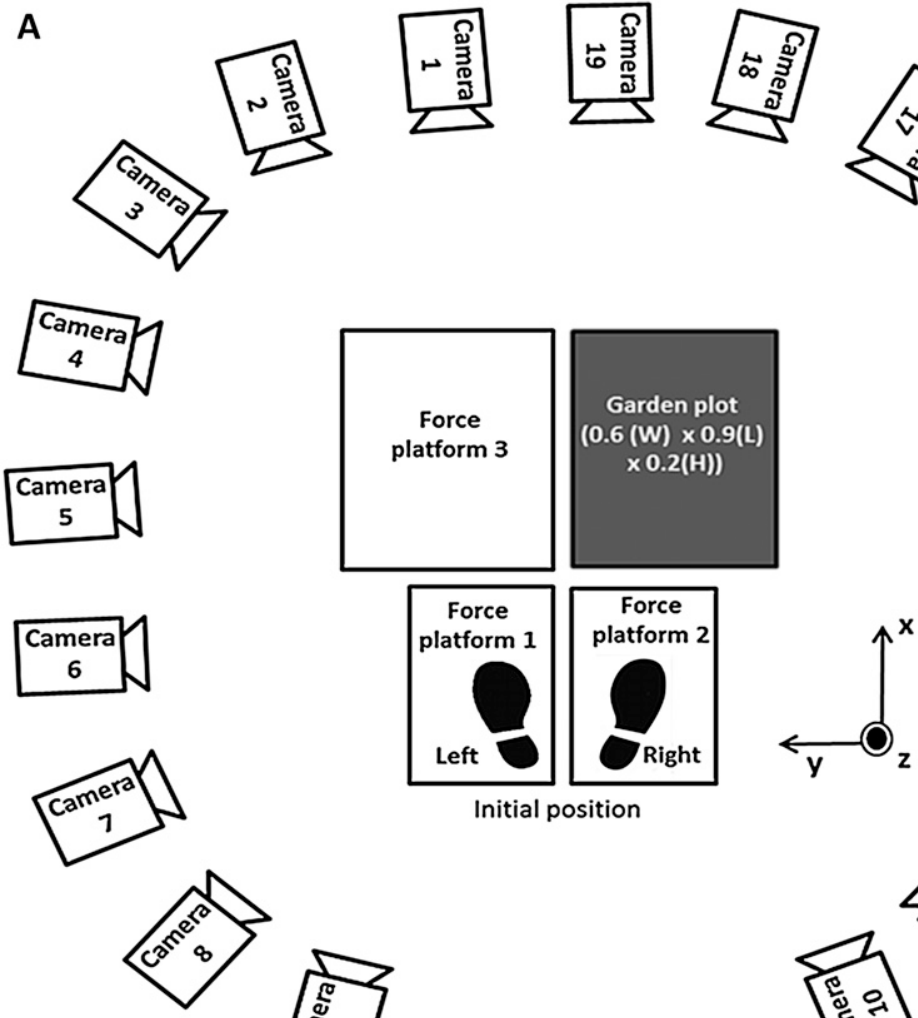

Initial position
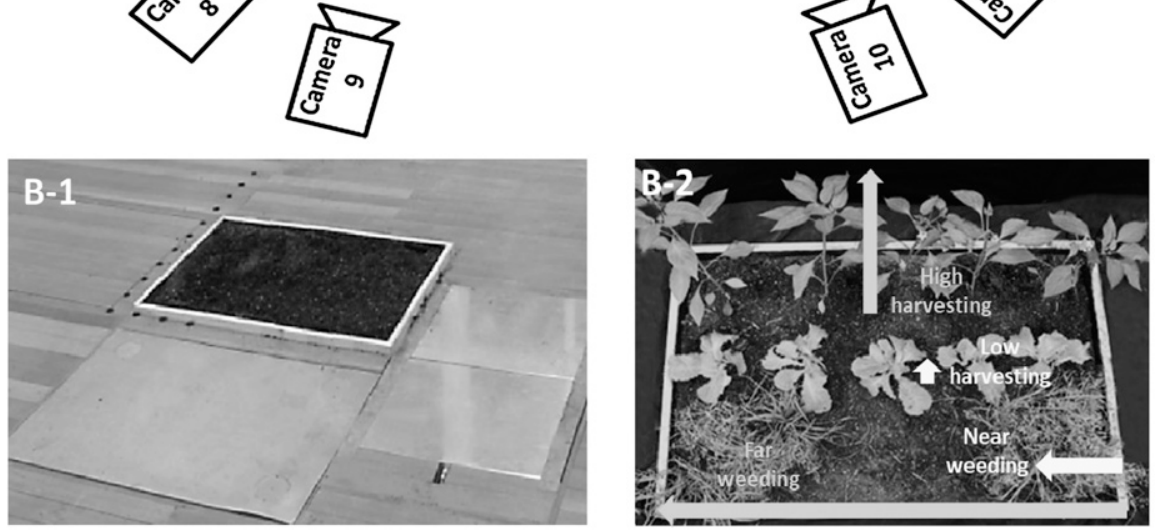

Fig. 1. (A) Plot design for the experimental setup. (B) A picture of a garden plot $[0.6$ (width $) \times 0.9($ length $) \times$ 0.2 (height)] in the experimental set-up. (B-1) Garden plot for raking, digging, sowing seeds, and transplanting plants. (B-2) Garden plot for weeding and harvesting. measured using an anthropometer (model ok7979; Samhwa, Seoul, South Korea) and body composition was assessed using a body fat analyzer (ioi 353; Jawon Medical, Gyeongsan, South Korea) while the subjects were shoeless. The length of the leg was assessed as the vertical distance from the right anterior superior iliac spine to the right medial malleolus, by using a measuring tape (model Rollfix; Hoechstmass, Sulzbach, Germany) (Sabharwal and Kumar, 2008).

Kinematic and kinetic analyses. A 3D motion analysis system (Qualisys Track Manager 2.7 build 783; Qualisys, Gothenburg, Sweden) was used for the analysis of kinematic factors such as CoM and the joint angles of the trunk and lower limbs, and kinetic factors such as joint moment (Fig. 1). A total of 19 infrared (IR) cameras (Qualisys Oqus700, Qualisys) were positioned around the testing area. The capture rate of the IR cameras was 200 frames/s.

During the performance of the HAs, the movement of ball-type reflective markers (diameter, $16 \mathrm{~mm}$ ) attached to each subject's body was recorded. A total of 55 IR markers were attached to five joint positions (i.e., shoulder, pelvis, sacrum, knee, and ankle) and seven body segment positions (i.e., head, trunk, upper arm, forearm, thigh, lower leg, and foot) based on a modified Helen Hayes marker attachment method (Collins et al., 2009; Wu et al., 2005). A 3D global coordinate system was set up for the calibration of a 3D motion analysis system that provides a standard coordinate for data analysis. It was used to record the initial positioning of the subjects by the cameras for 1 min by using an L-shaped frame and a T-shaped bar. When performing the HAs, movement direction was set based on the axis perpendicular to the planes of motion of the body, such as the sagittal plane, frontal plane, and horizontal plane, as follows: $x$ (forward-back), $y$ (lateral), and $z$ (vertical) directions.

The force platform was used to measure the GRF, which represents the interaction between the body and the ground during the HAs. This is the most commonly used method for assessing balance quantitatively during movement by calculating forces and torques in the $x$-, $y$-, and $z$-axes directions acting on the force platform while the subject performed motion (Piirtola and Era, 2006). Three force platforms (models 9281CA and 9287BA; Kistler Instruments, Winterthur, Switzerland; dimensions, $0.6 \times 0.4 \mathrm{~m}$ and $0.6 \times 0.9 \mathrm{~m}$ ) were positioned in the testing area, as shown in Fig. 1. The sampling rate of the force platforms was $100 \mathrm{~Hz}$, and the amplitude and range of voltage were set to $400 \mathrm{~dB}$ and $\pm 10 \mathrm{~V}$, respectively.

A portable 16-channel surface EMG (Desktop DTS; Noraxon, Scottsdale, AZ) was used for the kinetic analysis of muscle activation. A total of 16 axial and lower limb muscles that have been shown previously to be functionally agonistic during $\mathrm{HA}$ and functional activities of daily living were selected (Kuo et al., 2011; Park et al., 2014). Bipolar surface EMG electrodes 


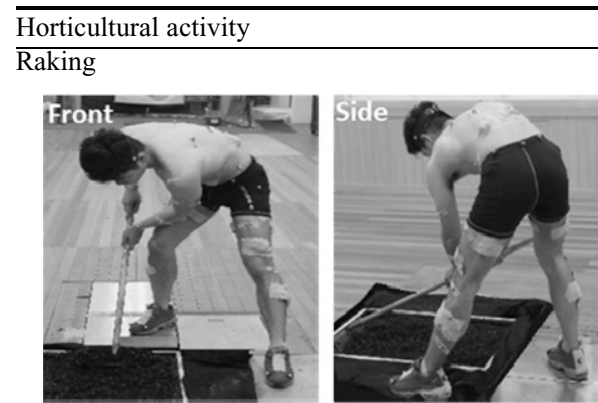

Digging

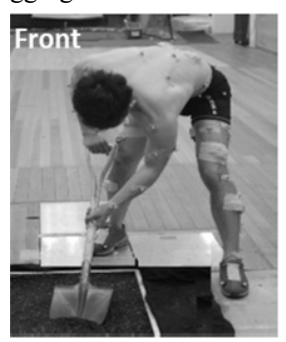

Sowing seeds

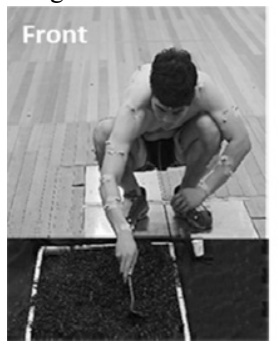

Transplanting plants

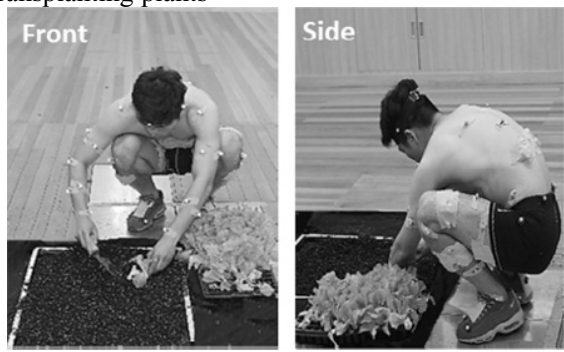

Weeding near and far distances
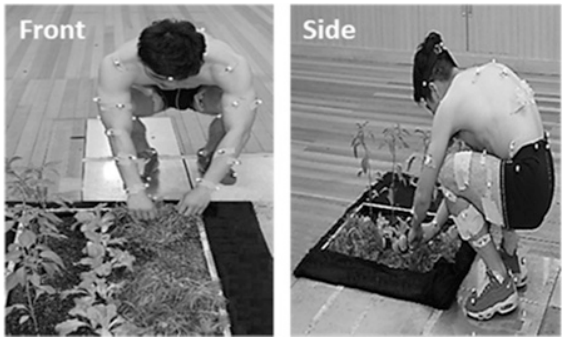

Harvesting low and high heights
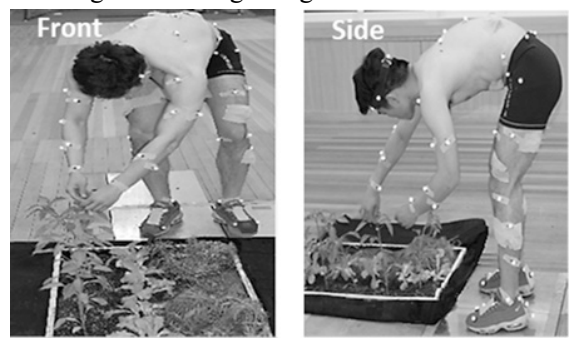

Descriptions

1) Standing with the feet shoulder width apart, holding onto the rake $(0.9 \mathrm{~kg})$ by placing the right hand at the end of the stick; 2) stepping forward with the left foot ahead of the right foot, holding the stick one third from the end; 3) reaching out as far as possible with the rake to position the blade properly at the horticultural task pot; 4) striking the rake onto the ground toward the front of the subject; 5) stepping back with the left foot.
1) Standing with the feet shoulder width apart, holding the handle of the shovel $(1.3 \mathrm{~kg})$ with the right hand; 2) stepping forward with the left foot ahead of the right foot, holding the middle of the handle of the shovel with the left hand; 3 ) reaching to plunge the blade of the shovel properly into the horticultural task pot; 4) digging and heaping the soil to the right side; 5) stepping back with the left foot.
1) Standing with the feet shoulder width apart, holding the handle of the hoe $(0.3 \mathrm{~kg})$ with the right hand; 2) squatting down (bending both legs horizontally); 3 ) reaching out as far as possible with the hoe to position the blade properly at the horticultural task pot; 4) striking the hand hoe onto the ground; 5) sowing seeds (Lactuca sativa) with both hands as a drill-seeding task; 6) standing up.
1) Standing with the feet shoulder width apart, holding the handle of the trowel $(0.1 \mathrm{~kg})$ with the right hand; 2) squatting down (bending both legs horizontally); 3) reaching to plunge the blade of the trowel properly into the horticultural task pot; 4) digging and heaping the soil to the right side; 5) transplanting one lettuce plant (Lactuca sativa) with both hands; 6) standing up.
1) Standing with the feet shoulder width apart; 2) squatting down (bending both legs horizontally); 3 ) reaching the right arm to the weeds (distance between the feet and weeds: near distance, $0.3 \mathrm{~m}$; far distance, $0.8 \mathrm{~m})$; 4) grasping the weeds with the right hand, pulling them out toward the body (frequency: bimanual, three times); 5) standing up.

1) Standing with the feet shoulder width apart; 2) stooping down, reaching the right arm to pick up the produce [low height, lettuce produce (Lactuca sativa) at $0.15 \mathrm{~m}$ above the ground; high height, pepper produce (Capsicum annuum) at $0.5 \mathrm{~m}$ above the ground]; 3 ) harvesting the produce with the right hand and then putting it in the left hand (frequency: bimanual, three times); 4) stretching up. 

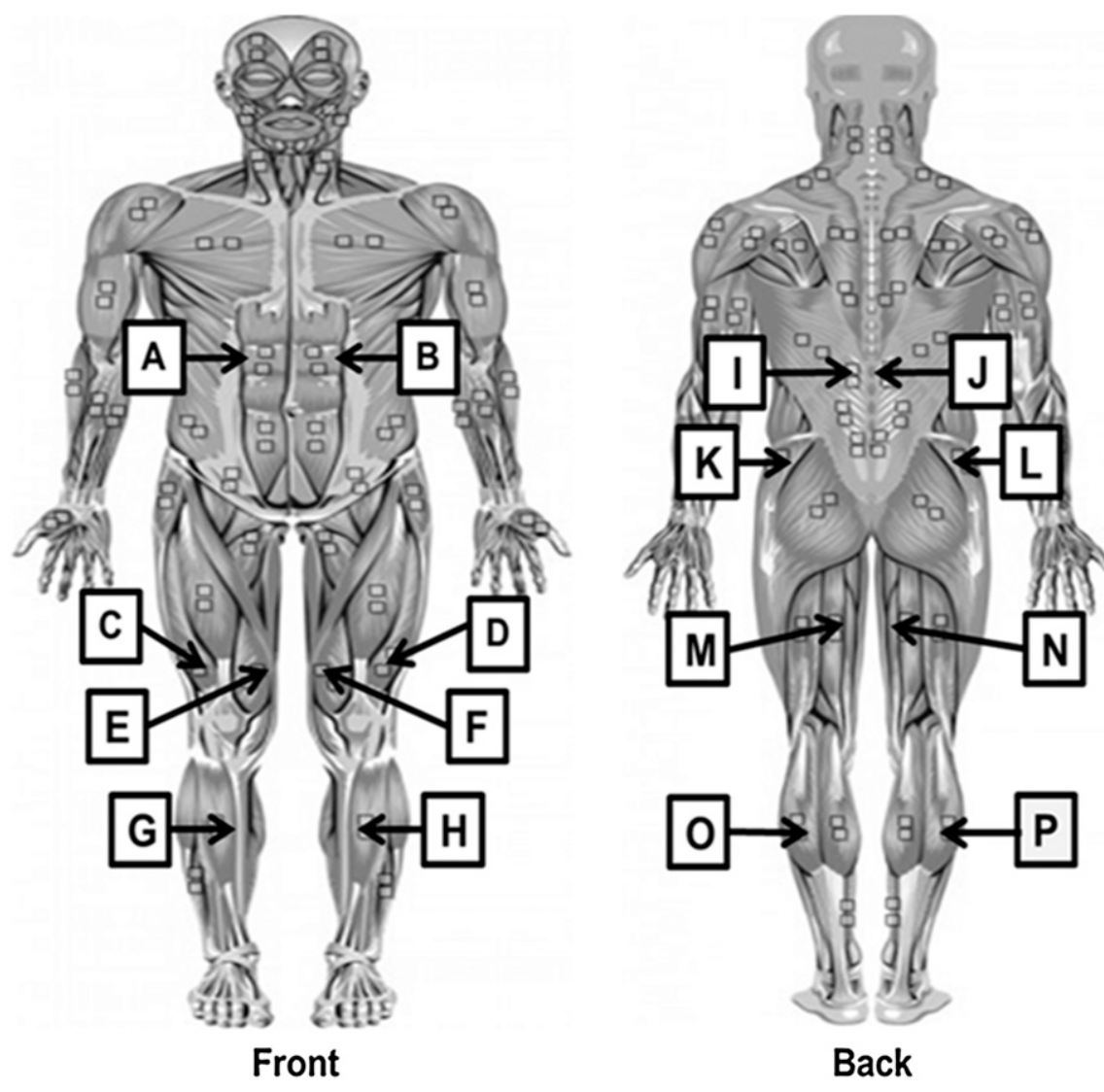

Fig. 2. Lower limb and axial muscles, the activity of which was measured using electromyography during eight horticultural activities using MyoResearch XP Clinical Edition 1.07 software (Noraxon, Scottsdale, AZ). (A) Right rectus abdominis; (B) left rectus abdominis; (C) right rectus femoris; (D) left rectus femoris; (E) right adductor magnus; (F) left adductor magnus; (G) right anterior tibial; (H) left anterior tibial; (I) left erector spinae; (J) right erector spinae; (K) left gluteus medius; (L) right gluteus medius; (M) left biceps femoris; (N) right biceps femoris; (O) left gastrocnemius; and (P) right gastrocnemius.

(Noraxon Dual EMG Electrode; diameter, $22 \mathrm{~mm}$; Noraxon) were attached on both sides of 10 lower limb muscles, 2 hip muscles, and 4 axial muscles during the eight HAs (Fig. 2). The force platforms and the EMG device were connected to the $3 \mathrm{D}$ motion analysis system through the A/D (analog to digital) board used for synchronizing measurement tools.

\section{Data analysis}

The kinematics and kinetic variables of the HAs were analyzed using Qualisys Track Manager software (2.11 build 2280, Qualisys). The raw data were rectified by applying the Butterworth fourth-order low-pass filter (cutoff frequency, $15 \mathrm{~Hz}$ ) (Donnelly et al., 2012). Human movement is mainly characterized by 5- to $20-\mathrm{Hz}$ low-frequency data, which can be interfered with easily by high-frequency mechanical and electrical noise (Hatze, 1990; Kristianslund et al., 2012). The low-pass filter is used to eliminate these interfering signals to improve the stability and confidence of the human movement frequency data (Chiari et al., 2005; Paolini et al., 2007).

The recorded two-dimensional image photography data were digitized and converted into $3 \mathrm{D}$ images using a nonlinear transformation method (Donnelly et al., 2012) to obtain the relative coordinates of the markers attached to the subject's joints.

The CoM and joint angle were computed based on the $x$-axis (sagittal plane), $y$-axis (coronal plane), and $z$-axis (transverse plane). The CoMs of the HAs were computed as the maximum shifting distance (measured in millimeters) between the left and right, front and back, and up and down directions. Joint angles were measured using the position of the flexion and extension in the sagittal plane, adduction and abduction in the frontal plane, and medial rotation and lateral rotation in the transverse plane of each joint through the inner product of the vector between two segments connected by the joints.

To analyze the joint movement pattern during the HAs, the total movement process from start to finish of each HA was set at $100 \%$, and the tendency of extension and flexion was shown. The joint moment was calculated using the acting rotational force between the two segments in the sagittal plane. To normalize the moment data according to the body composition of the subject, the subject's weight and mass were divided by the collected raw data [measured in $\mathrm{Nm} \cdot \mathrm{N}^{-1}$; torque (unit, newton meter) / force (unit, newton)].
The GRF is the force that acts on a body when the body makes contact with the ground. $\mathrm{CoP}$ is the point of application of the GRF (Porter, 2013). The GRF was calculated using the maximum vertical force $(\mathrm{N})$ generated on the foot from the ground; CoP was analyzed as the $\mathrm{CoP}$ positions of both feet in the left and right ( $x$-axis) and forwardback ( $y$-axis) directions during HA. CoP shifting was calculated as the maximum shifting distance (measured in millimeters) of the CoP during $\mathrm{HA}$; the dispersed distribution to the trajectory of the $\mathrm{CoP}$ was obtained by normalizing the total movement time (set at $100 \%$ ).

The collected analog signals through the surface EMG device were converted to digital signals in the wireless EMG analysis system, and the signals were analyzed using MyoResearch XP Master Edition (MyoResearch XP Clinical Edition 1.07, Noraxon). The raw EMG data (sampling rate, $1000 \mathrm{~Hz}$ ) were filtered to remove noise by using a band-pass digital filter with a cutoff frequency of $20 \mathrm{~Hz}$ (low) and $250 \mathrm{~Hz}$ (high), and smoothing (10 ms) (Flanagan et al., 2003; Park et al., 2014). In addition, for normalization of EMG data, the raw EMG data were converted to the percentage of maximum voluntary isomeric contraction (\%MVIC) data, which means the ratio of muscle activation required for an $\mathrm{HA}$ to achieve maximal voluntary contraction (MVC) of each muscle (Nishijima et al., 2010). To measure the MVC of each muscle, the subject was asked to exert maximum force at each muscle for 3 to $5 \mathrm{~s}$. The MVC was calculated based on the 2.5-s interval, including the point where MVIC occurred in the raw EMG signals (Konrad, 2005; Weinhandl et al., 2013).

\section{Statistics}

The kinematic and kinetic characteristics of the waist and lower limbs during the eight HAs were compared using one-way analysis of variance and Duncan's multiple range tests conducted with SPSS (version 24 for Windows; IBM, Armonk, NY). Independentsample $t$ tests and paired-sample $t$ tests were performed to examine homogeneity between joint angles of the waist and lower limbs of both sides, and to compare the characteristics between the subsequent HA motions. The significance level was set at $P<0.05$.

Demographic data such as age, height, body weight, body composition, leg length, and joint angles in the initial position were analyzed using descriptive statistics with Excel software (Microsoft Office 2007; Microsoft Corp., Redmond, WA).

\section{Results and Discussion}

\section{Phase definitions for HA motions}

The eight HAs - digging, raking, sowing seeds, transplanting plants, near-distance weeding, far-distance weeding, low-height harvesting, and high-height harvestingrequired stepping, squatting, and stooping, which are functional tasks for balance improvement training. Digging and raking were 
Table 3. Results of center of mass (CoM) for phases of the eight horticultural activities (mean $\pm \mathrm{SD}$ ) in the study of kinematic and kinetic analysis of horticultural activities for postural control and balance training.

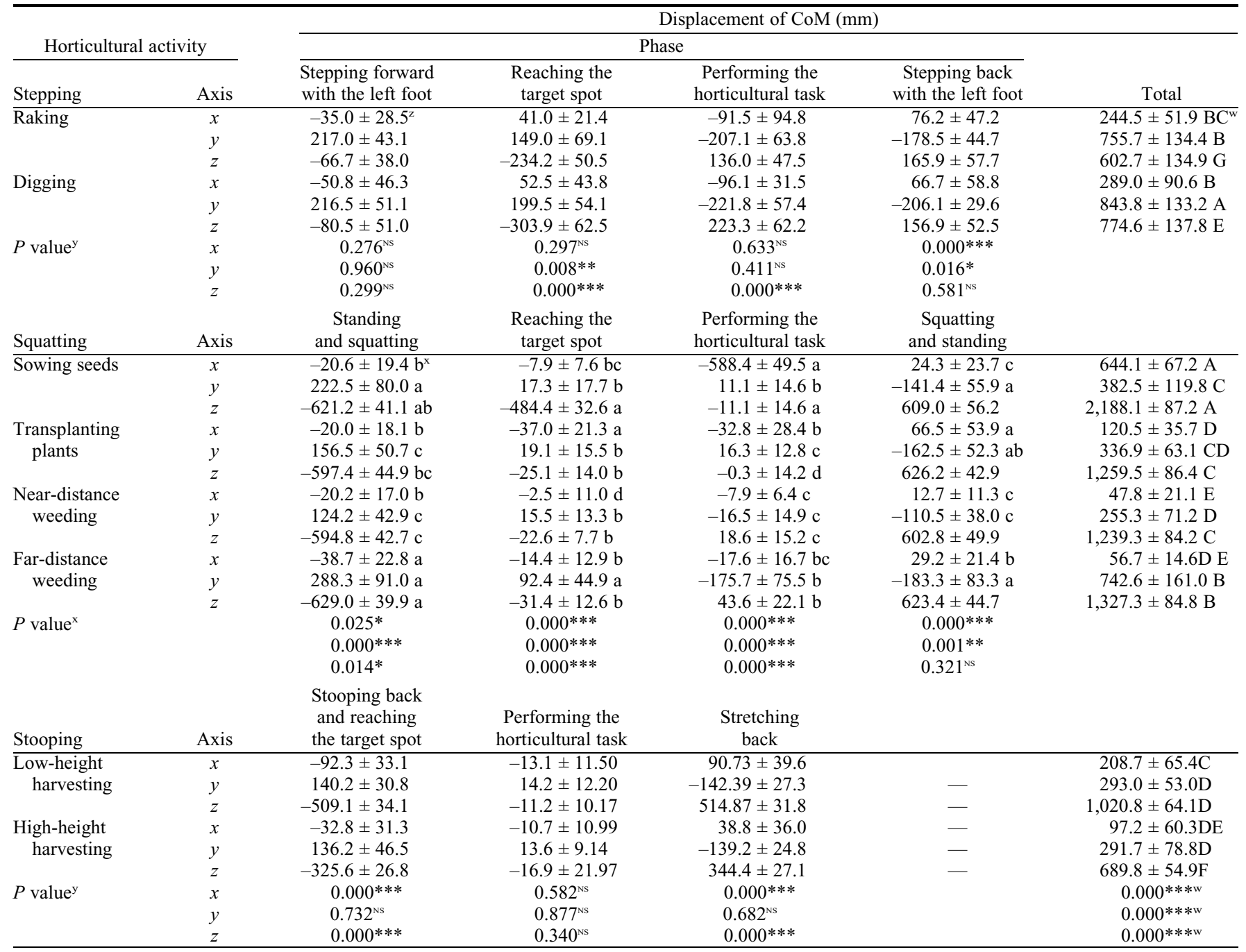

${ }^{\mathrm{z}}$ Positive and negative values $(+,-)$ mean that the CoM was moving in the following directions: $x$-axis $(+$, right;,- left $), y$-axis $(+$, anterior;,- lateral), $z$-axis (+, upward; -, downward).

${ }^{y}$ An independent-sample $t$ test was conducted to compare the means of displacement of raking and digging or low-height harvesting and high-height harvesting, respectively, at $P<0.05$.

${ }^{\mathrm{x}} \mathrm{A}$ one-way analysis of variance (ANOVA) was conducted to compare the means of displacement of CoM data ( $x$-, $y$-, and $z$-axes) for each phase in the four horticultural activities that classified squatting motion, with a significance of $P<0.05$. When the results of the ANOVA were statistically significant, a Duncan's multiple range test was conducted to determine the differences between the means of displacement of CoM data at $P<0.05$.

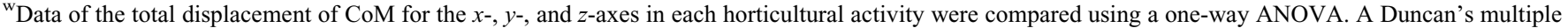
range test as post hoc analysis was conducted to determine the differences between the means of displacement of CoM data at $P<0.001$.

NS $, *, * *, * *$ Nonsignificant or significant at $P<0.05,0.01$, or 0.001 , respectively.

- $=$ no more phase.

Table 4. Results of ground reaction force of the eight horticultural activities (mean \pm SD) in the study of kinematic and kinetic analysis of horticultural activities for postural control and balance training.

\begin{tabular}{lccc}
\hline & \multicolumn{2}{c}{ Peak force $(\mathrm{N})$} & \\
\cline { 2 - 3 } Horticultural activity & Right & Left & $P$ value \\
\hline Raking & $733.7 \pm 100.8 \mathrm{a}^{\mathrm{z}}$ & $343.7 \pm 82.8 \mathrm{~b}$ & $0.000^{* * *}$ \\
Digging & $722.0 \pm 93.4 \mathrm{a}$ & $407.6 \pm 81.1 \mathrm{a}$ & $0.000^{* * *}$ \\
Sowing seeds & $458.7 \pm 86.2 \mathrm{bc}$ & $392.0 \pm 79.6 \mathrm{ab}$ & $0.001^{* *}$ \\
Transplanting plants & $471.7 \pm 76.7 \mathrm{bc}$ & $401.1 \pm 100.9 \mathrm{a}$ & $0.001^{* *}$ \\
Near-distance weeding & $451.6 \pm 55.3 \mathrm{bc}$ & $414.4 \pm 76.2 \mathrm{a}$ & $0.018^{*}$ \\
Far-distance weeding & $440.2 \pm 76.2 \mathrm{c}$ & $421.3 \pm 108.9 \mathrm{a}$ & $0.478^{\text {ss }}$ \\
Low-height harvesting & $506.5 \pm 96.0 \mathrm{~b}$ & $383.9 \pm 60.8 \mathrm{ab}$ & $0.000^{* * *}$ \\
High-height harvesting & $437.0 \pm 64.9 \mathrm{c}$ & $381.9 \pm 50.7 \mathrm{ab}$ & $0.001^{* *}$ \\
$P$ value & $0.000^{* * *}$ & $0.046^{*}$ & \\
\hline
\end{tabular}

${ }^{\mathrm{z}} \mathrm{A}$ one-way analysis of variance (ANOVA) test was conducted to compare the means of peak force data for each horticultural activity at $P<0.05$. When the results of the ANOVA test were statistically significant, a Duncan's multiple range test was conducted to determine the differences between the means of peak force at $P<0.05$.

${ }^{\mathrm{y}} \mathrm{An}$ independent-sample $t$ test was conducted to compare the right and left peak force data in each activity at $P<0.05$.

Ns, $*, * *, * *$ Nonsignificant or significant at $P<0.05,0.01$, or 0.001 , respectively. classified as stepping; sowing seeds, transplanting plants, near-distance weeding, and far-distance weeding were classified as squatting; and low-height harvesting and highheight harvesting were classified as stooping (data not shown).

The specific four phases within stepping were defined as 1) stepping forward with the left foot, 2) reaching the target spot, 3) performing the horticultural task, and 4) stepping back with the left foot. Squatting also consisted of four phases: 1) standing and squatting, 2) reaching the target spot, 3) performing the horticultural task, and 4) squatting and standing. Stooping consisted of three phases: 1) stooping back and reaching the target spot, 2) performing the horticultural task, and 3) stretching back. This 
phase of HA motion was defined as the movement between each event at which a specific posture appears (data not shown).

These phase definitions were similar to balance improvement training motions (Carty et al., 2011; Kuo et al., 2011). Down-

Table 5. Results of pathway of center of pressure $(\mathrm{CoP})$ for the eight horticultural activities ( $\mathrm{mean} \pm \mathrm{SD})$ in the study of kinematic and kinetic analysis of horticultural activities for postural control and balance training.

\begin{tabular}{|c|c|c|c|c|}
\hline \multirow[b]{3}{*}{ Horticultural activity } & \multicolumn{4}{|c|}{ Displacement of CoP (mm) } \\
\hline & \multicolumn{2}{|c|}{ Right } & \multicolumn{2}{|c|}{ Left } \\
\hline & $\begin{array}{c}\text { Mediolateral } \\
\text { (right direction) }\end{array}$ & $\begin{array}{l}\text { Anteroposterior } \\
\text { (front direction) }\end{array}$ & $\begin{array}{l}\text { Mediolateral } \\
\text { (left direction) }\end{array}$ & $\begin{array}{l}\text { Anteroposterior } \\
\text { (front direction) }\end{array}$ \\
\hline Raking & $23.1 \pm 22.2 \mathrm{abc}^{\mathrm{z}}$ & $29.0 \pm 13.5 \mathrm{~d}$ & $24.0 \pm 21.2 \mathrm{~b}$ & $40.3 \pm 25.9 \mathrm{~d}$ \\
\hline Digging & $18.1 \pm 12.9 \mathrm{bc}$ & $40.3 \pm 24.8 \mathrm{~d}$ & $18.1 \pm 14.4 \mathrm{~b}$ & $29.0 \pm 13.5 \mathrm{~d}$ \\
\hline Sowing seeds & $30.8 \pm 23.3 \mathrm{a}$ & $156.5 \pm 42.7 \mathrm{a}$ & $29.6 \pm 15.4 \mathrm{a}$ & $133.0 \pm 23.6 \mathrm{a}$ \\
\hline Transplanting plants & $34.8 \pm 16.7 \mathrm{a}$ & $128.0 \pm 47.0 \mathrm{~b}$ & $27.5 \pm 11.5 \mathrm{~b}$ & $123.6 \pm 45.6 b$ \\
\hline Near-distance weeding & $28.8 \pm 17.8 \mathrm{ab}$ & $110.0 \pm 44.4 \mathrm{bc}$ & $26.1 \pm 12.9 \mathrm{~b}$ & $113.1 \pm 42.4 \mathrm{bc}$ \\
\hline Far-distance weeding & $35.1 \pm 20.0 \mathrm{a}$ & $172.9 \pm 31.5 \mathrm{a}$ & $29.7 \pm 12.3 \mathrm{a}$ & $170.9 \pm 42.0 \mathrm{a}$ \\
\hline Low-height harvesting & $19.4 \pm 14.4 \mathrm{bc}$ & $126.1 \pm 48.6 \mathrm{~b}$ & $18.1 \pm 9.6 \mathrm{~b}$ & $101.2 \pm 37.4 \mathrm{c}$ \\
\hline High-height harvesting & $16.5 \pm 11.7 \mathrm{c}$ & $89.8 \pm 43.4 \mathrm{c}$ & $16.5 \pm 12.8 \mathrm{~b}$ & $90.1 \pm 58.1 \mathrm{c}$ \\
\hline$P$ value ${ }^{\mathrm{z}}$ & $0.000 * * *$ & $0.000 * * *$ & $0.009 * *$ & $0.000 * * *$ \\
\hline
\end{tabular}

${ }^{\mathrm{z}} \mathrm{A}$ one-way analysis of variance (ANOVA) was conducted to compare the means of total displacement of $\mathrm{CoP}$ for the right and left direction both feet in each horticultural activity at $P<0.05$. When the results of the ANOVA were statistically significant, a Duncan's multiple range test was conducted to determine the differences between the means of total displacement of $\mathrm{CoP}$ at $P<0.01$.

**, ***Significant at $P<0.01$ or 0.001 , respectively. ward reaching is a functional task used for balance and postural control training and clinical assessment of the risk of falls. To perform downward reaching, it is necessary to achieve motions such as stepping, squatting, and stooping (Gera et al., 2016; Hernandez et al., 2013). All HA motions included two phases in common: reaching the target spot and performing the horticultural task. During these two phases, the common characteristics of downward reaching were shown for performing the horticultural task successfully at the target spot in the garden area. Thus, the eight HAs in this study included a functional task for balance and postural control. Moreover, stepping, squatting, and stooping of the HAs were functional tasks used in the most basic movements of activities of daily living, such as ascending and descending stairs, picking an object from the floor or a low shelf, and toileting (Long and Pavalko, 2004).

\section{Stability of balance in HAs}

Center of mass. The CoM of the subjects shifted during all eight HAs. During all HA

Table 6. Results of joint angles of stepping motion in horticultural activities (mean $\pm \mathrm{SD}$ ) in the study of kinematic and kinetic analysis of horticultural activities for postural control and balance training.

\begin{tabular}{|c|c|c|c|c|c|c|}
\hline \multirow{3}{*}{$\frac{\text { Maximum joint angle }\left(^{\circ}\right)}{\text { Trunk }}$} & \multicolumn{6}{|c|}{ Horticultural activity } \\
\hline & \multicolumn{2}{|c|}{ Raking } & \multicolumn{2}{|c|}{ Digging } & \\
\hline & \multicolumn{4}{|c|}{ Duplex } & & \\
\hline \multicolumn{5}{|l|}{ Sagittal plane } & \multicolumn{2}{|c|}{$P$ value } \\
\hline Flexion & \multicolumn{2}{|c|}{$31.6 \pm 10.7$} & \multicolumn{2}{|c|}{$37.5 \pm 10.7$} & \multicolumn{2}{|c|}{$0.068^{\mathrm{Ns}}$} \\
\hline Extension & \multicolumn{2}{|c|}{ - } & \multicolumn{2}{|c|}{ - } & \multicolumn{2}{|c|}{ - } \\
\hline \multicolumn{7}{|l|}{ Frontal plane } \\
\hline Adduction & \multirow{2}{*}{\multicolumn{2}{|c|}{$8.8 \pm 4.4$}} & \multicolumn{2}{|c|}{$7.4 \pm 4.5$} & \multicolumn{2}{|c|}{$0.134^{\mathrm{Ns}}$} \\
\hline Abduction & & & \multicolumn{2}{|c|}{$3.7 \pm 3.1$} & \multicolumn{2}{|c|}{$0.810^{\mathrm{Ns}}$} \\
\hline \multicolumn{7}{|l|}{ Horizontal plane } \\
\hline Rt. rotation & \multicolumn{2}{|c|}{$14.0 \pm 5.1$} & \multirow{2}{*}{\multicolumn{2}{|c|}{$\begin{array}{r}12.9 \pm 6.0 \\
4.2 \pm 1.4\end{array}$}} & \multirow{2}{*}{\multicolumn{2}{|c|}{$\begin{array}{l}0.518^{\mathrm{NS}} \\
0.121^{\mathrm{Ns}}\end{array}$}} \\
\hline Lt. rotation & & & & & & \\
\hline Hip & Rt. & Lt. & Rt. & Lt. & Rt. & Lt. \\
\hline Sagittal plane & & & & & & \\
\hline Flexion & $60.8 \pm 22.5$ & $69.4 \pm 18.4$ & $68.9 \pm 20.7$ & $89.7 \pm 18.7$ & $0.204^{\mathrm{Ns}}$ & $0.001 * *$ \\
\hline Extension & $3.2 \pm 3.1$ & - & $2.3 \pm 1.9$ & - & $0.532^{\mathrm{Ns}}$ & - \\
\hline Frontal plane & & & & & & \\
\hline Rt. lateral bending & $4.5 \pm 4.0$ & $35.4 \pm 10.0$ & $2.5 \pm 2.3$ & $31.6 \pm 8.0$ & $0.234^{\mathrm{Ns}}$ & $0.356^{\mathrm{NS}}$ \\
\hline Lt. lateral bending & $10.4 \pm 6.2$ & - & $13.1 \pm 8.0$ & - & $0.211^{\mathrm{Ns}}$ & \\
\hline Horizontal plane & & & & & & \\
\hline Rt. rotation & $10.6 \pm 9.8$ & $27.2 \pm 10.6$ & $11.1 \pm 10.5$ & $26.0 \pm 8.4$ & $0.892^{\mathrm{NS}}$ & $0.154^{\mathrm{NS}}$ \\
\hline Lt. rotation & $13.0 \pm 9.0$ & - & $14.2 \pm 8.3$ & - & $0.880^{\mathrm{NS}}$ & - \\
\hline Knee & Rt. & Lt. & Rt. & Lt. & Rt. & Lt. \\
\hline Sagittal plane & & & & & & \\
\hline Flexion & $56.0 \pm 11.7$ & $27.8 \pm 12.7$ & $54.2 \pm 12.2$ & $42.5 \pm 13.5$ & $0.281^{\mathrm{Ns}}$ & $0.001 * *$ \\
\hline Extension & $4.5 \pm 4.2$ & $6.3 \pm 6.2$ & $3.7 \pm 1.1$ & $4.3 \pm 4.1$ & $0.228^{\mathrm{Ns}}$ & $0.384^{\mathrm{Ns}}$ \\
\hline Frontal plane & & & & & & \\
\hline Rt. lateral bending & $4.4 \pm 1.9$ & $4.1 \pm 3.9$ & $3.8 \pm 2.4$ & $4.5 \pm 3.6$ & $0.395^{\mathrm{Ns}}$ & $0.790^{\mathrm{NS}}$ \\
\hline Lt. lateral bending & $13.3 \pm 5.6$ & $5.7 \pm 3.9$ & $14.4 \pm 4.6$ & $8.3 \pm 5.9$ & $0.500^{\mathrm{NS}}$ & $0.050^{\mathrm{NS}}$ \\
\hline Horizontal plane & & & & & & \\
\hline Rt. rotation & $12.1 \pm 3.9$ & $17.7 \pm 9.5$ & $13.4 \pm 5.6$ & $14.8 \pm 8.3$ & $0.351^{\mathrm{Ns}}$ & $0.270^{\mathrm{NS}}$ \\
\hline Lt. rotation & $6.0 \pm 3.0$ & - & $8.7 \pm 8.6$ & - & $0.337^{\mathrm{Ns}}$ & - \\
\hline Ankle & Rt. & Lt. & Rt. & Lt. & Rt. & Lt. \\
\hline Sagittal plane & & & & & & \\
\hline Dorsiflexion & $8.3 \pm 5.2$ & - & $6.7 \pm 5.5$ & $18.4 \pm 5.8$ & $0.441^{\mathrm{Ns}}$ & - \\
\hline Plantar flexion & - & $39.9 \pm 11.6$ & $13.3 \pm 5.2$ & $37.3 \pm 13.6$ & - & $0.497^{\mathrm{Ns}}$ \\
\hline Frontal plane & & & & & & \\
\hline Rt. lateral bending & $13.2 \pm 6.5$ & $9.8 \pm 8.9$ & $12.0 \pm 7.8$ & $11.2 \pm 9.4$ & $0.619^{\mathrm{Ns}}$ & $0.651^{\mathrm{NS}}$ \\
\hline Lt. lateral bending & $8.8 \pm 7.5$ & $7.6 \pm 5.7$ & $10.0 \pm 6.1$ & $7.4 \pm 5.7$ & $0.252^{\mathrm{Ns}}$ & $0.853^{\mathrm{Ns}}$ \\
\hline Horizontal plane & & & & & & \\
\hline Rt. rotation & - & $37.3 \pm 13.6$ & - & $39.9 \pm 11.6$ & - & $0.000 * * *$ \\
\hline Lt. rotation & $8.3 \pm 5.2$ & - & $6.2 \pm 5.8$ & - & $0.001 * *$ & - \\
\hline
\end{tabular}

${ }^{2}$ An independent-sample $t$ test was conducted to compare the means of the joint angle of raking and digging at $P<0.05$.

Ns $, * *, * * *$ Nonsignificant or significant at $P<0.01$ or 0.001 , respectively.

Rt. = right; Lt. $=$ left; $-=$ not detected. 


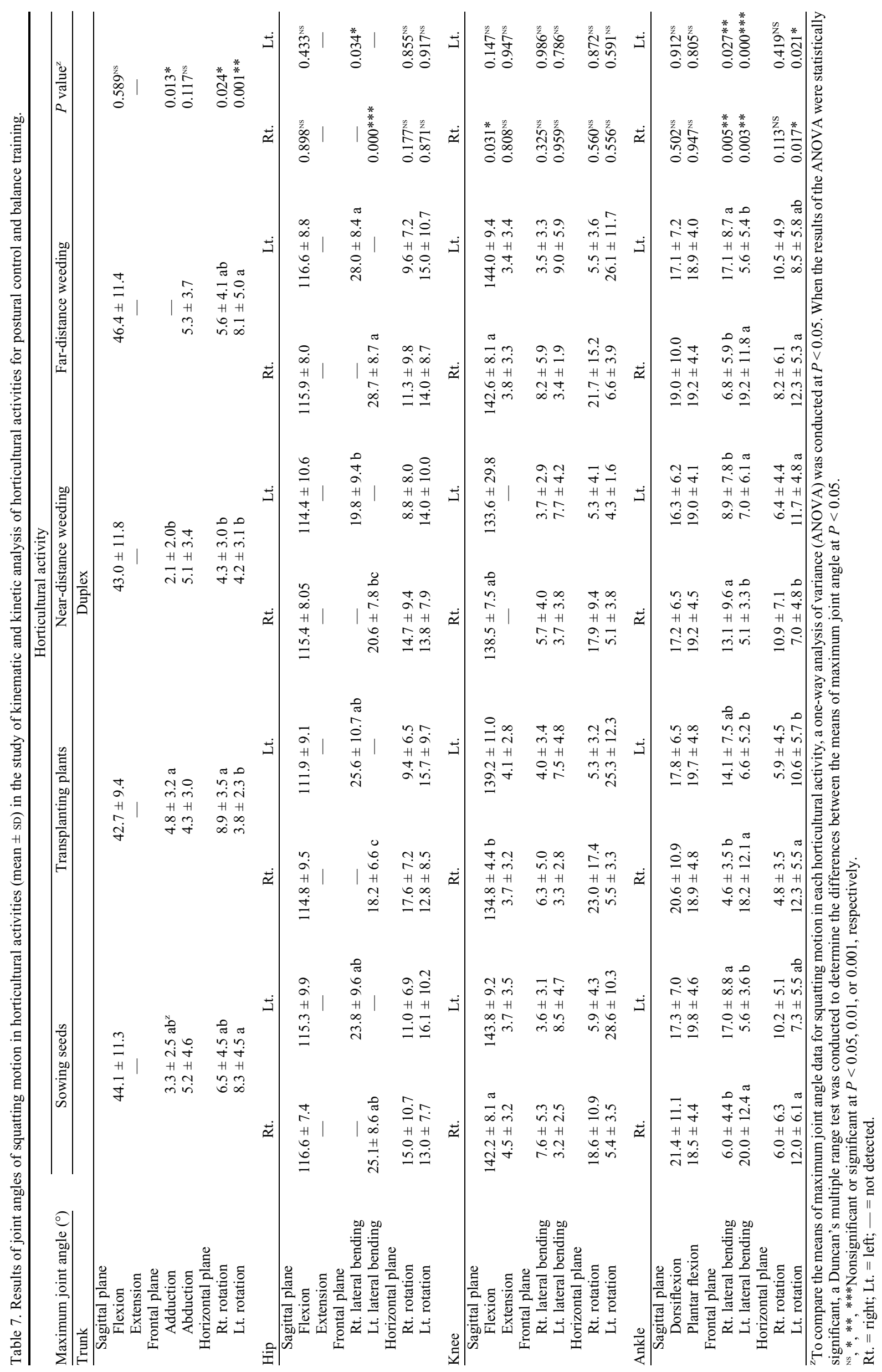


Table 8. Results of joint angles of stooping motion in horticultural activities (mean $\pm \mathrm{SD}$ ) in the study of kinematic and kinetic analysis of horticultural activities for postural control and balance training.

\begin{tabular}{|c|c|c|c|c|c|c|}
\hline \multirow{3}{*}{$\frac{\text { Maximum joint angle }\left(^{\circ}\right)}{\text { Trunk }}$} & \multicolumn{6}{|c|}{ Horticultural activity } \\
\hline & \multicolumn{2}{|c|}{ High-ht harvesting } & \multicolumn{2}{|c|}{ Low ht harvesting } & \multirow{2}{*}{\multicolumn{2}{|c|}{$P$ value ${ }^{z}$}} \\
\hline & \multicolumn{4}{|c|}{ Duplex } & & \\
\hline \multicolumn{5}{|l|}{ Sagittal plane } & \\
\hline Flexion & \multicolumn{2}{|c|}{$42.9 \pm 11.1$} & \multicolumn{2}{|c|}{$48.8 \pm 11.1$} & \\
\hline Extension & \multicolumn{2}{|c|}{ - } & \multicolumn{2}{|c|}{-} & \multicolumn{2}{|c|}{0.001} \\
\hline \multicolumn{7}{|l|}{ Frontal plane } \\
\hline Adduction & \multicolumn{2}{|c|}{$3.3 \pm 2.6$} & \multicolumn{2}{|c|}{$3.8 \pm 2.8$} & \multicolumn{2}{|c|}{$0.569^{\mathrm{NS}}$} \\
\hline Abduction & \multicolumn{2}{|c|}{$2.9 \pm 2.1$} & \multicolumn{2}{|c|}{$3.6 \pm 2.5$} & \multicolumn{2}{|c|}{$0.405^{\mathrm{Ns}}$} \\
\hline \multicolumn{7}{|l|}{ Horizontal plane } \\
\hline Rt. Rotation & \multirow{2}{*}{\multicolumn{2}{|c|}{$4.3 \pm 3.0$}} & \multicolumn{2}{|c|}{$5.8 \pm 4.2$} & \multicolumn{2}{|c|}{$0.250^{\mathrm{NS}}$} \\
\hline Lt. rotation & & & & & & \\
\hline Hip & Rt. & Lt. & Lt. & Lt. & Lt. & Lt. \\
\hline Sagittal plane & & & & & & \\
\hline Flexion & $75.0 \pm 9.2$ & $75.8 \pm 10.2$ & $108.8 \pm 7.4$ & $107.4 \pm 8.9$ & $0.000^{* * *}$ & $0.000 * * *$ \\
\hline Extension & $4.8 \pm 3.7$ & $3.8 \pm 3.3$ & $5.8 \pm 3.2$ & $5.0 \pm 3.7$ & $0.503^{\mathrm{NS}}$ & $0.516^{\mathrm{NS}}$ \\
\hline Frontal plane & & & & & & \\
\hline Rt. lateral bending & $2.6 \pm 2.3$ & $2.3 \pm 1.4$ & $4.9 \pm 4.6$ & $16.0 \pm 8.2$ & $0.283^{\mathrm{NS}}$ & $0.000 * * *$ \\
\hline Lt. lateral bending & $7.0 \pm 4.2$ & $7.1 \pm 4.2$ & $7.4 \pm 4.2$ & $6.6 \pm 4.5$ & $0.715^{\mathrm{NS}}$ & $0.035^{*}$ \\
\hline Horizontal plane & & & & & & \\
\hline Rt. Rotation & $4.1 \pm 3.1$ & $11.8 \pm 7.1$ & $5.55 \pm 4.4$ & $12.2 \pm 7.0$ & $0.602^{\mathrm{NS}}$ & $0.867^{\mathrm{Ns}}$ \\
\hline Lt. rotation & $14.9 \pm 7.8$ & $6.7 \pm 5.5$ & $16.0 \pm 7.9$ & $6.7 \pm 6.0$ & $0.655^{\mathrm{NS}}$ & $0.978^{\mathrm{Ns}}$ \\
\hline Knee & Rt. & Lt. & Rt. & Lt. & Rt. & Lt. \\
\hline Sagittal plane & & & & & & \\
\hline Flexion & $17.7 \pm 11.4$ & $20.2 \pm 12.9$ & $56.2 \pm 22.1$ & $61.5 \pm 21.6$ & $0.000 * * *$ & $0.000 * * *$ \\
\hline Extension & - & - & - & - & - & - \\
\hline Frontal plane & & & & & & \\
\hline Rt. lateral bending & $5.3 \pm 4.1$ & $3.5 \pm 2.9$ & $6.7 \pm 5.6$ & $4.8 \pm 4.5$ & $0.398^{\mathrm{NS}}$ & $0.344^{\mathrm{NS}}$ \\
\hline Lt. lateral bending & $4.3 \pm 2.0$ & $3.7 \pm 1.8$ & $5.1 \pm 3.6$ & $8.8 \pm 3.7$ & $0.556^{\mathrm{NS}}$ & $0.000 * * *$ \\
\hline Horizontal plane & & & & & & \\
\hline Rt. Rotation & $3.7 \pm 2.9$ & $7.6 \pm 4.3$ & $5.5 \pm 4.5$ & $7.4 \pm 4.3$ & $0.121^{\mathrm{NS}}$ & $0.870^{\mathrm{NS}}$ \\
\hline Lt. rotation & $6.1 \pm 3.2$ & $3.8 \pm 3.2$ & $5.8 \pm 5.4$ & $3.7 \pm 3.5$ & $0.662^{\mathrm{NS}}$ & $0.671^{\mathrm{NS}}$ \\
\hline Ankle & Rt. & Lt. & Rt. & Lt. & Rt. & Lt. \\
\hline Sagittal plane & & & & & & \\
\hline Dorsiflexion & - & - & $6.0 \pm 5.4$ & $6.6 \pm 4.8$ & - & - \\
\hline Plantar flexion & $25.3 \pm 5.9$ & $24.9 \pm 6.5$ & $19.7 \pm 4.4$ & $19.4 \pm 4.1$ & $0.001 * *$ & $0.001 * *$ \\
\hline Frontal plane & & & & & & \\
\hline Rt. lateral bending & $5.3 \pm 3.3$ & $6.9 \pm 4.9$ & $6.2 \pm 3.7$ & $8.9 \pm 5.0$ & $0.514^{\mathrm{Ns}}$ & $0.269^{\mathrm{NS}}$ \\
\hline Lt. lateral bending & $4.1 \pm 3.2$ & $4.4 \pm 3.1$ & $7.0 \pm 6.0$ & $5.1 \pm 3.7$ & $0.115^{\mathrm{Ns}}$ & $0.597^{\mathrm{Ns}}$ \\
\hline Horizontal plane & & & & & & \\
\hline Rt. Rotation & - & $10.3 \pm 5.6$ & - & $12.0 \pm 5.4$ & - & $0.314^{\mathrm{NS}}$ \\
\hline Lt. rotation & $11.3 \pm 5.0$ & - & $11.0 \pm 5.1$ & - & $0.856^{\mathrm{NS}}$ & - \\
\hline
\end{tabular}

${ }^{\mathrm{z}} \mathrm{An}$ independent sample $t$ test was conducted to compare the means of the joint angle of high- and low-height harvesting at $P<0.05$.

Ns, ${ }^{*}, * *, * * *$ Nonsignificant or significant at $P<0.05,0.01$, or 0.001 , respectively.

Rt., right; Lt., left; $-=$ not detected.

motions, the CoM from the standing-upright phase to the reaching-the-target-spot phase shifted forward and downward from the subjects' body. After the performing-the-horticultural-task phase, the CoM shifted back to the subjects' body while returning to the standing-upright phase.

The total movement distance of the CoM among all the HAs was statistically significant $(P=0.001)$ (Table 3$)$. Among all the eight HAs, the HA with the largest shifting of CoM in the anteroposterior direction was digging $(843.8 \pm 133.2 \mathrm{~mm})$, whereas that in the vertical direction was sowing seeds $(2188.1 \pm 87.2 \mathrm{~mm})(P=0.001)$.

The characteristic of $\mathrm{CoM}$ shifting during HAs makes balance unstable. The sense of balance is reduced when the CoM of the body moves out of the BoS, which represents the side-to-side and front-to-back boundaries of the two feet (Horak, 2006). To control the instability of balance, the central nervous system (CNS) performs motor control before HAs are conducted. As a result of motor control, deliberate motor strategies and movement of the musculoskeletal system of the CNS are generated automatically to stabilize balance. These processes maintain balance, ultimately allowing subjects to perform the activities successfully without falling (Weaver et al., 2017).

Ground reaction force. HAs have been characterized as applying a constant force of the body against gravity on the ground. The GRF of HAs showed a significant difference depending on the type of HA (Table 4) $(P=0.05)$. The GRF of the right foot was the greatest in stepping motions such as raking $(733.7 \pm 100.8 \mathrm{~N})$ and digging $(722.0 \pm 93.4$ N) $(P=0.001)$. The GRF of the left foot was significantly greater in far-distance weeding $(421.3 \pm 108.9 \mathrm{~N})$, near-distance weeding $(414.4 \pm 76.2 \mathrm{~N})$, digging $(407.6 \pm 81.1 \mathrm{~N})$, and transplanting plants $(401.1 \pm 100.9 \mathrm{~N})$ than in the other activities $(P=0.05)$. The GRF of the right foot was greater than that of the left foot for all of the eight HAs except far-distance weeding $(P=0.05)$.
Center of pressure. The CoP trajectory, the center position of the GRF generated during HAs, was represented by the variance distribution of the CoP with the right-left direction and the forward-backward direction. All eight HAs showed the CoP movement of both feet. The CoP at the origin coordinates, located at the center of the feet during the initial position, was moved toward the end of the toes until the reaching-thetarget-spot phase. In the performing-thehorticultural-task phase, the $\mathrm{CoP}$ position at the end of the toes was maintained constantly. In other words, the CoPs of the right foot and the left foot commonly moved from the right to the front and the left to the front, respectively. After the performing-thehorticultural-task phase, the CoP returned to its origin coordinates (data not shown).

There was a significant difference in the distance of maximum $\mathrm{CoP}$ shifting during HAs among the activities $(P=0.01)$ (Table 5). Among all the eight HAs, the greatest activities of $\mathrm{CoP}$ shifting were 
Table 9. Results of joint moment ( $x$-axis) for the eight horticultural activities (mean $\pm \mathrm{SD}$ ) in the study of kinematic and kinetic analysis of horticultural activities for postural control and balance training.

\begin{tabular}{|c|c|c|c|c|c|c|c|c|}
\hline \multirow{2}{*}{ Horticultural activity } & \multicolumn{8}{|c|}{ Peak joint moment $(\mathrm{Nm} / \mathrm{N})$} \\
\hline & \multicolumn{2}{|c|}{ Trunk } & \multicolumn{2}{|c|}{ Hip } & \multicolumn{2}{|c|}{ Knee } & \multicolumn{2}{|c|}{ Ankle } \\
\hline Raking & $0.27 \pm 0.04 \mathrm{bcd}^{\mathrm{z}}$ & $0.03 \pm 0.02$ & $0.04 \pm 0.02 \mathrm{a}$ & $0.12 \pm 0.03 \mathrm{bc}$ & $0.11 \pm 0.04 \mathrm{ab}$ & $0.07 \pm 0.05 \mathrm{ab}$ & $0.00 \pm 0.00 \mathrm{~b}$ & $0.12 \pm 0.04 \mathrm{ab}$ \\
\hline Sowing seeds & $0.25 \pm 0.04 \mathrm{~cd}$ & $0.05 \pm 0.02$ & $0.03 \pm 0.01 \mathrm{~b}$ & $0.11 \pm 0.03 \mathrm{bc}$ & $0.11 \pm 0.03 \mathrm{ab}$ & $0.06 \pm 0.06 \mathrm{abc}$ & $0.00 \pm 0.00 \mathrm{~b}$ & $0.11 \pm 0.06 \mathrm{~cd}$ \\
\hline Transplanting plants & $0.26 \pm 0.03 \mathrm{bcd}$ & $0.05 \pm 0.02$ & $0.03 \pm 0.01 \mathrm{~b}$ & $0.13 \pm 0.03 \mathrm{~b}$ & $0.11 \pm 0.02 \mathrm{ab}$ & $0.07 \pm 0.03 \mathrm{ab}$ & $0.04 \pm 0.01 \mathrm{a}$ & $0.08 \pm 0.02 \mathrm{~d}$ \\
\hline Near-distance weeding & $0.27 \pm 0.05 b c$ & $0.04 \pm 0.02$ & $0.02 \pm 0.01 \mathrm{~b}$ & $0.12 \pm 0.03 \mathrm{bc}$ & $0.12 \pm 0.02 \mathrm{a}$ & $0.05 \pm 0.04 \mathrm{abcd}$ & $0.01 \pm 0.01 \mathrm{~b}$ & $0.09 \pm 0.03 \mathrm{~d}$ \\
\hline Far-distance weeding & $0.29 \pm 0.04 \mathrm{ab}$ & $0.06 \pm 0.02$ & $0.03 \pm 0.01 \mathrm{~b}$ & $0.11 \pm 0.02 \mathrm{c}$ & $0.10 \pm 0.02 \mathrm{bc}$ & $0.05 \pm 0.05 \mathrm{bcd}$ & $0.00 \pm 0.00 \mathrm{~b}$ & $0.09 \pm 0.04 \mathrm{~d}$ \\
\hline$P$ value $^{\mathrm{z}}$ & $0.000 * * *$ & $0.069^{\mathrm{Ns}}$ & $0.000 * * *$ & $0.000^{* * *}$ & $0.000^{* * *}$ & $0.003 * *$ & $0.012 *$ & $0.000^{* * *}$ \\
\hline
\end{tabular}

${ }^{\mathrm{z}} \mathrm{A}$ one-way analysis of variance (ANOVA) was conducted to compare the means of peak joint flexion and extension moment data for each horticultural activity at $P<0.05$. When the results of the ANOVA were statistically significant, a Duncan's multiple range test was conducted to determine the differences between the means of peak joint moment at $P<0.01$.

Ns, $*, * *, * * *$ Nonsignificant or significant at $P<0.05,0.01$, or 0.001 , respectively.

$-=$ not detected.

observed in sowing seeds and far-distance weeding (Table 5). For instance, the CoP of sowing seeds was shifted to the right by $30.8 \pm 23.3 \mathrm{~mm}$ and the anterior by $156.5 \pm$ $42.7 \mathrm{~mm}$ from the origin coordinates $(x$ : $424.9 \pm 39.4 \mathrm{~mm}, y: 1218.9 \pm 41.3 \mathrm{~mm}$ ) of the right foot, and to the left by $29.6 \pm$ $15.4 \mathrm{~mm}$ and the anterior by $133.0 \pm$ $23.6 \mathrm{~mm}$ from the origin coordinates $(x$ : $432.2 \pm 28.3 \mathrm{~mm}, y: 1218.9 \pm 43.3 \mathrm{~mm})$ of the left foot $(P=0.01)$.

To control the instability of balance that occurs as the CoM moves toward the edges of the BoS resulting from the dynamic motion of HAs, the generation of the GRF and the movement of the CoP occur in the two feet such that the CoM no longer deviates out from the edges of the BoS (Glinka, 2013; Weaver et al., 2017). The CoM located at the edges of BoS - a controlled factor to maintain balance of the body-is controlled by the GRF and CoP. The directions of shifting of the CoM and CoP were reported to have a similar correlation (Glinka, 2013; Winter et al., 1996).

The results of this study suggest that the differences in the movement strategies, such as GRF generation and CoP shifting among the HAs, can be used as therapeutic techniques for learning movement strategies and controlling the difficulty of HAs in horticultural therapy as balance improvement training (Latash and Nicholas, 1996).

\section{Musculoskeletal system movement to maintain balance stability in HAs}

Joint angle. All of the lower joint movements of HAs were found to require movement of the trunk, left and right hips, left and right knees, and left and right ankles through 3D motion analysis (Tables 6-8). The maximum joint angle of stepping, squatting, and stooping of HAs showed similar kinematic characteristics according to each motion. Within the same motion, there was a joint movement characteristic that showed a significant difference according to HAs $(P=$ 0.05) (Tables 6-8).

In the case of stepping, there was a significant difference in the maximal joint angle of the left hip, left knee, and the left and right ankle between raking and digging $(P=0.01)$. During digging, the left hip flexion (digging: $89.7 \pm 18.7^{\circ}$, raking: $\left.69.4 \pm 18.4^{\circ}\right)$, left knee flexion (digging: $42.5 \pm 13.5^{\circ}$, raking: $27.8 \pm$ $12.7^{\circ}$ ), and left ankle right rotation (digging: $39.9 \pm 11.6^{\circ}$, raking: $37.3 \pm 13.6^{\circ}$ ) were significantly greater than those during raking. On the other hand, the left rotation of the right ankle (digging: $6.2 \pm 5.8^{\circ}$, raking: $8.3 \pm 5.1^{\circ}$ ) was greater in raking than in digging (Table 6).

When performing HAs, the joint pattern of the lower limb showed that 1 ) the flexion occurred at the beginning of HAs in the initial position, where the body joint was almost $0^{\circ}$; 2 ) the maximum flexion was reached and maintained statically during the reachingthe-target-spot phase and the performingthe-horticultural-task phase; and 3) after performing the horticultural task, the extension returned to the initial position (data not shown). The characteristics of HAs in which maximum flexion was maintained constantly were observed at $17.0 \%$ to $80.0 \%$ in raking, $17.0 \%$ to $85.0 \%$ in digging, $12.0 \%$ to $90.0 \%$ in sowing seeds, $14.0 \%$ to $89.0 \%$ in transplanting plants, $16.0 \%$ to $86.0 \%$ in near-distance weeding, $14.0 \%$ to $80.0 \%$ in far-distance weeding, $27.0 \%$ to $77.0 \%$ in low-height harvesting, and $23.0 \%$ to $75.0 \%$ in high-height harvesting standardized with the total movement time (set to $100 \%$ ). This feature is likely to help improve the range of motion by extending viscoelastic tissue creep, the connective tissue in a joint, and more flexibly (McGill and Brown, 1992; Toosizadeh and Nussbaum, 2013). The kinetic and kinematic characteristics of the HAs in this study were similar to those of the functional tasks for balance improvement training, such as stepping, squatting, and stooping. The joint angle of all HAs showed a greater tendency of flexion of the trunk, hip, knee, and ankle with more COM shifting (Glinka, 2013).

Joint moment. In all the HA motions, flexion and extension moments occurred (Table 9). When performing HAs, the flexion moment of the trunk was found to be the greatest among the other joint moments
$(P=0.001)$. The maximum flexion and extension moments of all the joints except the extension moment of the trunk were significantly different according to the HAs $(P=0.05)$.

Digging was found to have the greatest flexion $\left(0.04 \pm 0.01 \mathrm{Nm} \cdot \mathrm{N}^{-1}\right)$ and extension moment $\left(0.16 \pm 0.04 \mathrm{Nm} \cdot \mathrm{N}^{-1}\right)$ of the hip, extension moment $\left(0.08 \pm 0.05 \mathrm{Nm} \cdot \mathrm{N}^{-1}\right)$ of the knee, and extension moment $(0.13 \pm 0.04$ $\left.\mathrm{Nm} \cdot \mathrm{N}^{-1}\right)$ of the ankle among all HAs $(P=$ 0.01). Among all the HAs, low-height harvesting had the greatest trunk flexion moment $\left(0.31 \pm 0.11 \mathrm{Nm} \cdot \mathrm{N}^{-1}\right)(P=0.001)($ Table 8$)$. The degree of joint moment generation is affected by the range of motion, angular velocity, and weight loading during the motion. When the flexion of the joint increases, the joint moment tends to become greater (Butler et al., 2010; Hemmerich et al., 2006). Therefore, it is considered that the greatest trunk flexion moment occurred during lowheight harvesting because it requires the greatest trunk flexion $\left(48.82 \pm 11.1^{\circ}\right)$ among the HAs.

Muscle activation. The HAs showed similar characteristics of muscle activation in the lower limb according to the motion (stepping, squatting, and stooping; Table 10). Stepping (i.e., digging and raking) was found to show significantly greater muscle activation than the other muscles in the left gluteus medius $(P=0.001)$. Sowing seeds and transplanting plants in squatting showed significantly greater muscle activation in the left tibialis anterior than in the other muscles. In the case of weeding when squatting, near-distance weeding showed the greatest muscle activation in both rectus femoris, whereas far-distance weeding showed the greatest activation in both tibialis anterior $(P=0.001)$.

The HA motions in the current study showed lower muscle activations than the functional squatting and reaching, although the muscle activation pattern was similar (Kuo et al., 2011). This difference is attributed to the fact that squatting of HAs contained one more phase (i.e., squatting and standing) than functional squatting and reaching, so that a greater numeric value of 


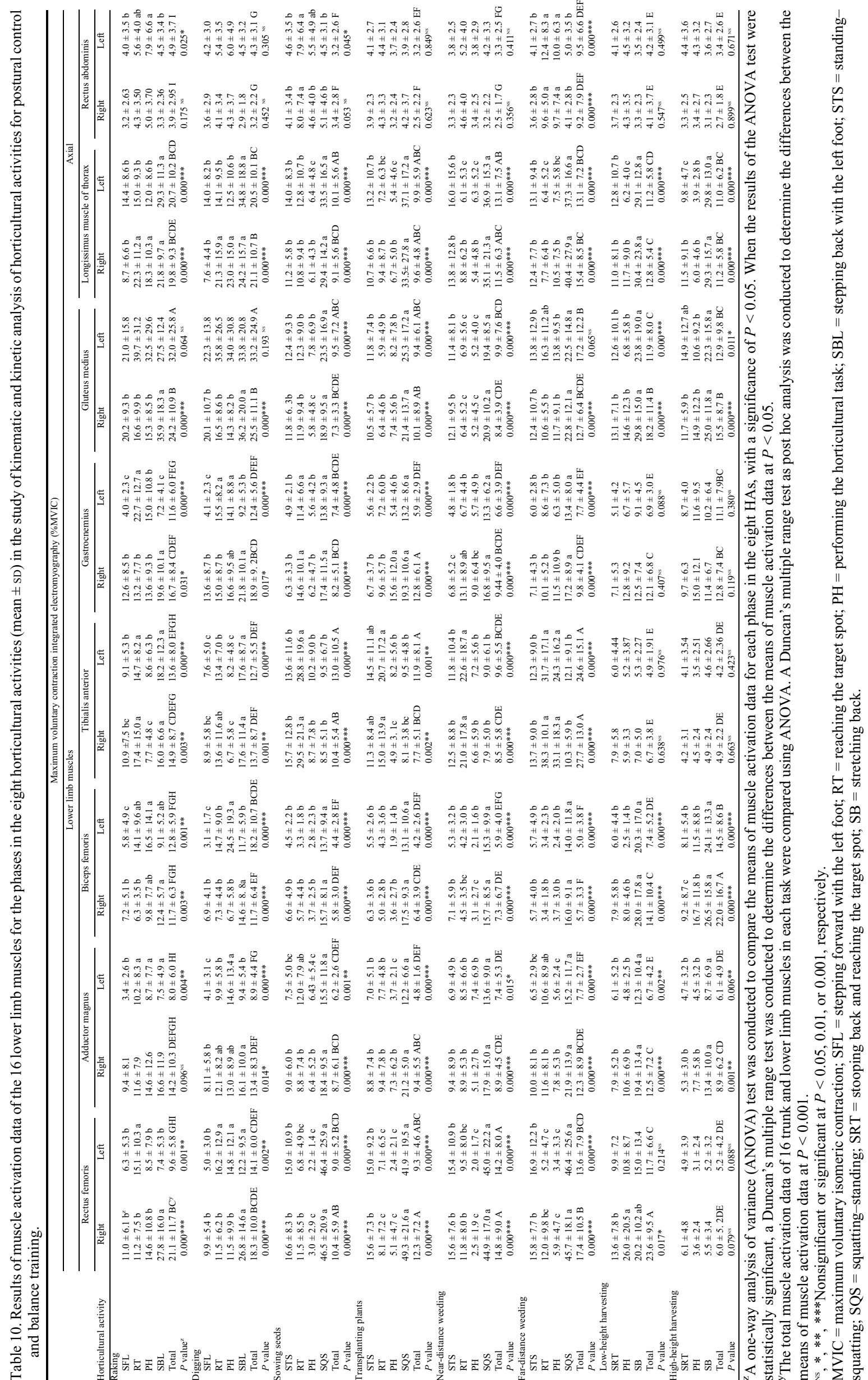


muscle activation was integrated with the MVC (Nishijima et al., 2010).

When performing all the HA motions, the activation of the longissimus muscle of the thorax was significantly greater during the last phase of each HA motion, such as the stepping-back-with-the-left foot, the squatting-and-standing, and stretching-back phases $(P=0.001)$. The rectus abdominis showed greater muscle activation in the reaching-the-target-spot phase during sowing seeds and far-distance weeding $(P=0.05)$. It is believed that returning to standing and reaching the arm can be performed successfully only when the trunk, pelvis, and hip joints are fixed. Therefore, the longissimus muscle of the thorax and the rectus abdominis, which support the trunk joint, seemed to be highly activated (Kuo et al., 2011; McGill, 1995).

In conclusion, this study investigated balance instability by shifting the CoM during lower limb motion in common HAs using kinematic and kinetic analyses. In addition, the generation of the GRF, movement of the $\mathrm{CoP}$, and coordination of the joint and muscle in the lower limb were found to be motor strategies for HAs to maintain an unstable balance and control posture. These results showed that HA motions can be used in rehabilitation therapy for balance improvement training for injured veterans, stroke victims, and so on, and that the methods should be applied directly to investigate horticulture for rehabilitation. This study suggests that HAs can be used in taskoriented training for the disabled by repeatedly incorporating functional tasks such as stepping, squatting, and stooping engaged in during those activities (Rensink et al., 2009). Referring to these findings, horticultural therapists can develop a horticultural therapy program into therapeutic techniques in the practical application for the disabled. Last, the scientific and objective indicators derived from this study will serve as reference data for developing a horticultural therapy program for balance improvement training. Future studies are needed to analyze the kinematic and kinetic characteristics of HA in subjects with impairments of and disabilities in balance or the lower limbs. A bigger sample size may need to help for generalizability of the study results.

\section{Literature Cited}

Aurbach, M., K. Wagner, F. Süß, and S. Dendorfer. 2017. Implementation and validation of human kinematics measured using IMUs for musculoskeletal simulations by the evaluation of joint reaction forces. Intl. Federation Medical Biological Eng. 62:205-211.

Butler, R.J., P.J. Plisky, C. Southers, C. Scoma, and K.B. Kiesel. 2010. Biomechanical analysis of the different classifications of the functional movement screen deep squat test. Sports Biomech. 9:270-279.

Carty, C.P., P. Mills, and R. Barrett. 2011. Recovery from forward loss of balance in young and older adults using the stepping strategy. Gait Posture 33:261-267.
Chen, T.Y. and M.C. Janke. 2012. Gardening as a potential activity to reduce falls in older adults. J. Aging Phys. Act. 20:15-31.

Chiari, L., C.U. Della, A. Leardini, and A. Cappozzo. 2005. Human movement analysis using stereophotogrammetry. Part 2: Instrumental errors. Gait Posture 21:197-211.

Collins, T.D., S.N. Ghoussayni, D.J. Ewins, and J.A. Kent. 2009. A six degrees-of-freedom marker set for gait analysis: Repeatability and comparison with a modified Helen Hayes set. Gait Posture 30:173-180.

Donnelly, C.J., D.G. Lloyd, B.C. Elliott, and J.A. Reinbolt. 2012. Optimizing whole-body kinematics to minimize valgus knee loading during sidestepping: Implications for ACL injury risk. J. Biomech. 45:1491-1497.

Flanagan, S., G.J. Salem, M.Y. Wang, S.E. Sanker, and G.A. Greendale. 2003. Squatting exercises in older adults: Kinematic and kinetic comparisons. Med. Sci. Sports Exerc. 35:635-643.

Gera, G., K.E. McGlade, D.S. Reisman, and J.P. Scholz. 2016. Trunk muscle coordination during upward and downward reaching in stroke survivors. Mot. Contr. 20:50-69.

Glinka, M.N. 2013. The effect of aging on movement characteristics and postural control during stooping and crouching tasks. Waterloo Univ., Waterloo, Canada, Master's thesis.

Hatch, J., K.M. Gill-Body, and L.G. Portney. 2003. Determinants of balance confidence in community-dwelling elderly people. Phys. Ther. 83:1072-1079.

Hatze, H. 1990. Data conditioning and differentiation techniques, p. 237-248. In: N. Berme and A. Cappozzo (eds.). Biomechanics of human movement: Applications in rehabilitation, sports and ergonomics. Bertec Corporation, Worthington, $\mathrm{OH}$.

Hemmerich, A., H. Brown, S. Smith, S.S. Marthandam, and U.P. Wyss. 2006. Hip, knee, and ankle kinematics of high range of motion activities of daily living. J. Orthop. Res. 24:770-781.

Hernandez, M.E., J.A. Ashton-Miller, and N.B. Alexander. 2013. Age-related differences in maintenance of balance during forward reach to the floor. J. Gerontol. A Biol. Sci. Med. Sci. 68:960-967.

Horak, F.B. 2006. Postural orientation and equilibrium: What do we need to know about neura control of balance to prevent falls? Age Ageing 35(Suppl. 2):ii7-ii11.

Hrysomallis, C. 2011. Balance ability and athletic performance. Sports Med. 41:221-232.

Hwang, S., Y. Kim, and Y. Kim. 2009. Lower extremity joint kinetics and lumbar curvature during squat and stoop lifting. BMC Musculoskelet. Disord. 10:15.

Konrad, P. 2005. The ABC of EMG: A practical introduction to kinesiological electromyography, p. 30-35. Noraxon Inc., Scottsdale, AZ.

Kristianslund, E., T. Krosshaug, and A.J. Van den Bogert. 2012. Effect of low pass filtering on joint moments from inverse dynamics: Implications for injury prevention. J. Biomech. 45:666-671.

Kulas, A.S., T. Hortobágyi, and P. DeVita. 2012. Trunk position modulates anterior cruciate ligament forces and strains during a singleleg squat. Clin. Biomech. (Bristol, Avon) 27: $16-21$.

Kuo, F.C., W.P. Kao, H.I. Chen, and C.Z. Hong. 2011. Squat-to-reach task in older and young adults: Kinematic and electromyographic analyses. Gait Posture 33:124-129.

Latash, M.L. and J.J. Nicholas. 1996. Motor control research in rehabilitation medicine. Disabil. Rehabil. 18:293-299.
Long, J.S. and E. Pavalko. 2004. Comparing alternative measures of functional limitation. Med. Care 42:19-27.

McGill, S.M. 1995. The mechanics of torso flexion: Situps and standing dynamic flexion manoeuvres. Clin. Biomech. (Bristol, Avon) 10:184 192.

McGill, S.M. and S. Brown. 1992. Creep response of the lumbar spine to prolonged full flexion. Clin. Biomech. (Bristol, Avon) 7:43-46.

Murphy, M.A., K.S. Sunnerhagen, B. Johnels, and C. Willn. 2006. Three-dimensional kinematic motion analysis of a daily activity drinking from a glass: A pilot study. J. Neuroeng. Rehabil. 3:1-11.

Nishijima, Y., T. Kato, M. Yoshizawa, M. Miyashita, and H. Iida. 2010. Application of the segment weight dynamic movement method to the normalization of gait EMG amplitude. J. Electromyogr. Kinesiol. 20:550-557.

Paolini, G., U. Della Croce, P. Riley, and D.C. Kerrigan. 2007. Testing a multiunit instrumented treadmill for kinetic analysis of locomotion task in static and dynamic loading conditions. Med. Eng. Phys. 29:404 411.

Park, S.A., A.Y. Lee, J.J. Kim, K.S. Lee, J.M. So, and K.C. Son. 2014. Electromyographic analysis of upper and lower limbs muscles during gardening tasks. Weonye Gwahag Gisulji 32:710-720.

Park, S.A., S.R. Oh, K.S. Lee, and K.C. Son 2013. Electromyographic analysis of upper limb and hand muscles during horticultural activity motions. HortTechnology 23:5156.

Park, S.A. and C.A. Shoemaker. 2009. Observing body position of older adults while gardening for health benefits and risks. Act. Adaptation Aging 3:31-38.

Piirtola, M. and P. Era. 2006. Force platform measurements as predictors of falls among older people: A review. Gerontology 52:1-16.

Porter, S.B. 2013. Tidy's physiotherapy, p. 331365. In: J. Richards, A. Chohan, and R. Erande (eds.). Biomechanics. Elsevier Ltd., New York, NY

Rensink, M., M. Schuurmans, E. Lindeman, and T. Hafsteinsdottir. 2009. Task-oriented training in rehabilitation after stroke: Systematic review. J. Adv. Nurs. 65:737-754.

Sabharwal, S. and A. Kumar. 2008. Methods for assessing leg length discrepancy. Clin. Orthod. Res. 466:2910-2922.

Shin, S. and S. Demura. 2012. Examination of balance ability evaluated by a stipulated tempo step test. Arch. Gerontol. Geriatr. 55:45-48.

Termoz, N., S.E. Halliday, D.A. Winter, J.S. Frank, A.E. Patla, and F. Prince. 2008. The control of upright stance in young, elderly and persons with Parkinson's disease. Gait Posture 27:463 470.

Toosizadeh, N. and M.A. Nussbaum. 2013. Creep deformation of the human trunk in response to prolonged and repetitive flexion: Measuring and modeling the effect of external moment and flexion rate. Ann. Biomed. Eng. 41:11501161

Turner, L.W., M.A. Bass, L. Ting, and B. Brown. 2002. Influence of yard work and weight training on bone mineral density among older U.S. women. J. Women Aging 14:139-149.

Verra, M.L., F. Angst, T. Beck, S. Lehmann, R. Brioschi, R. Schneiter, and A. Aeschlimann. 2012. Horticultural therapy for patients with chronic musculoskeletal pain: Results of 
a pilot study. Altern. Ther. Health Med. 18 (2):44-50.

Weaver, T.B., M.N. Glinka, and A.C. Laing. 2017. Stooping, crouching, and standing: Characterizing balance control strategies across postures. J. Biomech. 53(28):90-96.

Weinhandl, J.T., J.E. Earl-Boehm, K.T. Ebersole, W.E. Huddleston, B.S. Armstrong, and K.M O'connor. 2013. Anticipatory effects on anterior cruciate ligament loading during sidestep cutting. Clin. Biomech. (Bristol, Avon) 28:655-663.

Winter, D.A., F. Prince, J.S. Frank, C. Powell, and K.F. Zabjek. 1996. Unified theory regarding A/P and $\mathrm{M} / \mathrm{L}$ balance in quiet stance. J. Neurophysiol. 75:2334-2343.

World Health Organization. 1995. Physical status: The use and interpretation of anthropometry. Report of a WHO Expert Committee. Rpt. no.:
WHO Tech. Rpt. Ser. No. 854. World Health Organization, Geneva, Switzerland.

Wu, G., F.C. Van der Helm, H.D. Veeger, M. Makhsous, P. Van Roy, C. Anglin, J. Nagels, A.R. Karduna, K. McQuade, X. Wang, and F.W. Werner. 2005. ISB recommendation on definitions of joint coordinate systems of various joints for the reporting of human joint motion. Part II: Shoulder, elbow, wrist and hand. J. Biomech. 38:981-992. 